\title{
Modularity design of the bamboo plastic fiber forming machine
}

\author{
Nguyen Thanh $\mathrm{Nam}^{1, *}$, and Nguyen Hoang Hiep ${ }^{2}$ \\ ${ }^{1}$ Faculty of Mechanical Engineering, Industrial University of Ho Chi Minh City, Vietnam \\ ${ }^{2}$ Faculty of Mechanical Engineering, Vinh Long University of Technology and Education
}

\begin{abstract}
Currently, the research on the application of bamboo wood plastic fibers to 3D printing technology in Vietnam is limited. Almost all studies mainly focus on the application of natural polymers (wood, rubber, coir..) but ignore a rich natural polymer source, popular in Vietnam: bamboo. In addition, the quality of wood plastic fibers applied in 3D printing technology has not responded to the requirements of consumers. The durability of 3D printed parts that is based on wood plastic fibers is not high. Surface gloss of parts after implementation is still rough. During the $3 \mathrm{D}$ printing process of wood plastic fibers material, the nozzle is still always clogged due to the blockage of wood pulp. Therefore, the study of technology and equipment for the fabrication of bamboo wood fibers and research on the effect of technological parameters on the finished bamboowood-plastic fiber properties is necessary and should be urgently carried out. The paper proposes a new approach to structure modularization of the bamboo wood plastic fiber forming machine by using mostly standard parts, thus improving the quality and reducing the cost of the machine and bamboo wood plastic fiber material for the 3D printer.
\end{abstract}

\section{Introduction}

Currently, the event of the global warming is evident, so scientists have studied a variety of green and environmentally friendly materials to restrict partly the human serious problem. Naturally derived composites are being studied more and more, not only because they could limit the environmental pollution but also prevent the depletion of natural resources due to over exploitation [1].

Wood plastic composite (WPC) that is a new type of composite material, including wood pulp and its constituent resin, is recommended as a logical solution with the addition of some additives or compatible substances. WPC has many superior features than natural wood, one of them is corrosion resistance, rot, termites and unabsorbed water to the fibers inside [2]. An alkaline treatment of wood pulp or plastic as Polylactic Acid (PLA) also increases the water resistance of the WPC, however, this reduces its mechanical properties.

Nowadays, FDM technology is the most popular 3D printing technology in which the process of extruding molten plastic material in a nozzle and then forming layers that will form a block structure after solidification. Because the machining principle of FDM

${ }^{*}$ Corresponding author: nguyenthanhnam@iuh.edu.vn 
technology is extremely simple, it applies to many different materials, and green composite is an extremely potential material. Scientists have conducted a lot of researches on creating fiber-like green composite products used in this technology, and they are often called wood-based plastic fibers.

In the study [3], the authors used pineapple fibers, banana peel fibers and bamboo fibers to create wood-based plastic fiber sheets based on epoxy. Composite is made of high mechanical properties, suitable for many industries and they also have the advantage of being low cost and easy to degrade.

In the study [4], the authors presented an overview of the process of creating wood plastic fibers from the extrusion process that is applied to the material additive technology. They also presented the opportunities and challenges of green composite fibers from extruders in the application of $3 \mathrm{D}$ printing technology.

In the study [5], the researchers made an overview of the machines as well as materials, used in the production of bamboo wood plastic fibers. They also proposed all the requirements for $3 \mathrm{D}$ printed bamboo wood plastic fibers to have good product quality: the diameter of plastic fibers must be in the range of $1.75-1.8 \mathrm{~mm}$; maximum particle size is $0.27-0.3 \mathrm{~mm}$, if it is bigger as about $0.4 \mathrm{~mm}$, it will cause nozzle jamming; the suitable machining temperature is about $180^{\circ}$.

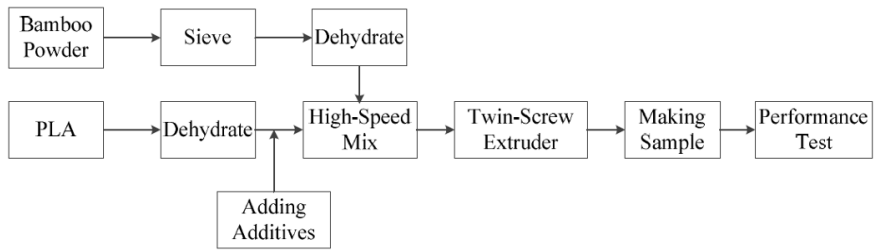

Fig. 1. The process of creating bamboo plastic fiber for 3D printer [5]

In the process of producing bamboo wood plastic fibers, as discussed above, there are many machines that are required to participate.

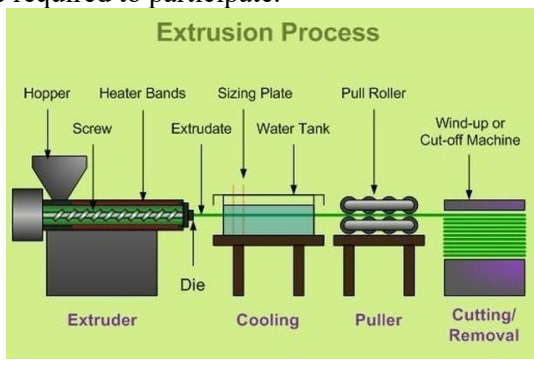

Fig. 2. Schema of basic machines for the production of bamboo plastic fiber [6]

Currently, with the strong development of composite materials technology, scientists increasingly focus on the development and application of green composites in industrial and civil fields. The application of natural wood fibers in the composite forming process with polymers to synthesize outstanding properties of wood fibers such as durability, hardness... and polymer properties such as water resistance, flexibility... With the advancement of 3D printing technology, scientists have also studied the creation of wood plastic fibers applied in this technology, initially creating basic products.

$3 \mathrm{D}$ printed bamboo resin fiber forming process: treated bamboo powder $(20 \%)$, PP $(52.5 \%)$, and PLA $(22.5 \%)$ are mixed with maleated polypropylene (MAPP) (5\%) with 
High speed mixer for 8 minutes. This mixture is then fed into a 2 -screw extruder to produce wood-plastic pellets. From there, these bamboo wood plastic pellets are fed into a single screw extruder to form the product [7].
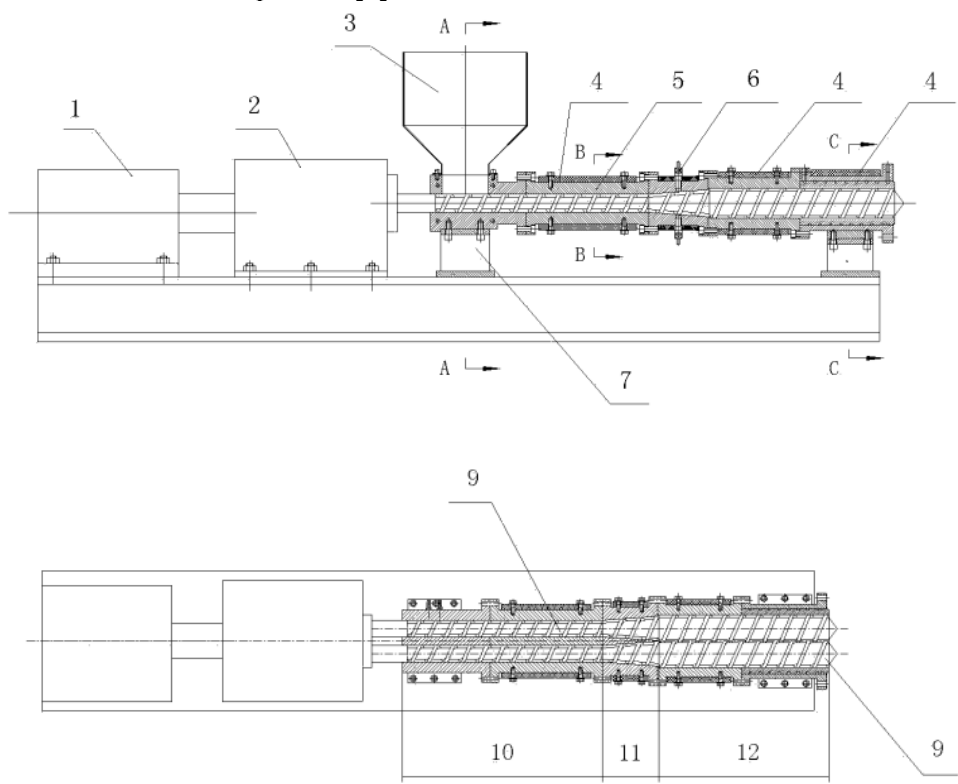

Fig. 3. Structure of extruding bamboo plastic fiber machine with double screw of [8]

Figure 3 shows the construction of the single-screw extruder of the invention [8]. All the 2-screw extruder parts are cited as in the following: 1: Electric motor; 2: Gearbox reducer; 3: Feeding hopper; 4: Thermistor heating; 5: Extruder housing; 6: Cooling water drainage; 7: Support structure; 8: Machine base; 9: 2-screw extrusion; 10: Feeding area; 11: Melting area; Region 12: Flow stable area. The extrusion by two screws facilitates the polymer flows along only one direction, limiting backflow. In addition, due to the properties of 2-screws, the material is mixed more efficiently than extruding with onescrew. The 2-screw structure is also studied by the authors, with the first design, one screw has a normal structure while the other is joined by 3 small screws in 3 divided regions above. That structure is logical to replace the extruded screw much more when it was damaged.

The authors mention the functional structure in which there are two extruders' screws with different sizes, but one screw that extends through all three regions, one that extends only through the last two regions. This helps to reduce the screw material and costs of machine. In the other side, it improves also the productivity because the feed area only needs to pre-melt the material, so one screw is also possible.

The above studies displayed preliminary processing methods of performing bamboo wood plastic fibers as well as the advantages and limitations of bamboo wood plastic fibers, but there has not been an innovated technology to develop products in practice. Therefore, it is necessary to develop new technology to create bamboo-wood plastic fiber, improve quality and reduce product costs. 


\section{The structure analysis method}

\subsection{Description the system}

Setting up the diagram of the relation between function and structure of the machine [9], [10].

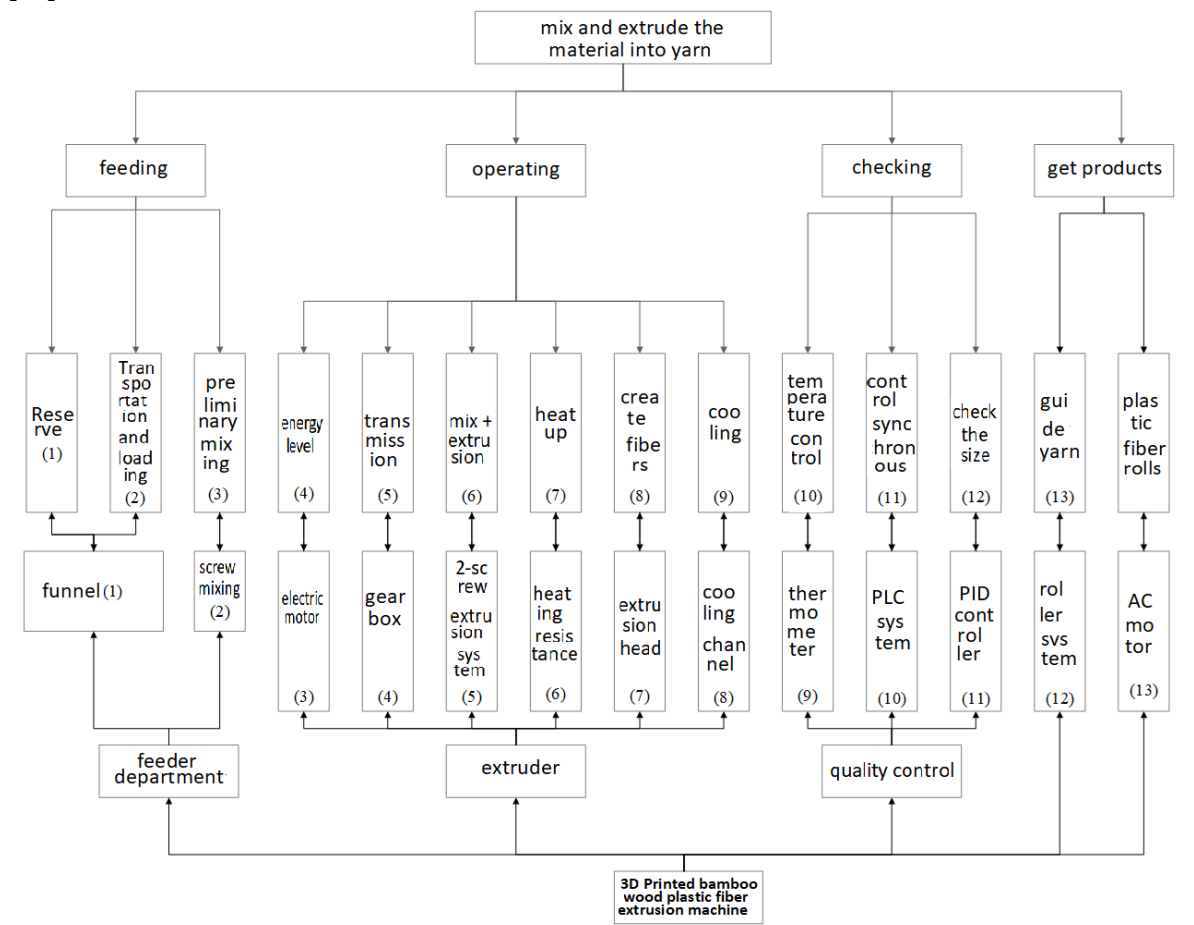

Fig. 4. Schema of the relation between Function and Structure of the machine design [11]

The system composes:

(1) Storing and feeding hopper.

(2) Preliminary mixing by screw.

(3) Power supply by electric motor.

(4) Transmission by gearbox, spur gear transmission and coupling.

(5) Mixing and extruding wood plastic mixture by twin extrusion screw in cylinder.

(6) Application of thermal strip to melt the resin.

(7) Creating yarn by the extruder,

(8) Cooling system to cool the hot extruded plastic fibers,

(9) Temperature control by sensors,

(10) Control and synchronization by PLC system,

(11) Check dimension by PID system,

(12) Leading bamboo wood plastic fiber by roller system,

(13) An AC motor for winding the filament.

When starting the system, the plastic particles and bamboo powder are fed to the hopper where they are properly quantified and pre-mixed in the feed hopper by a mixing screw that 
received the rotation from the motor via gear transmission and flexible shaft. Reversing twin-screw extrusion system is installed to increase the mixing efficiency. The partial heating of the screws is carried out by solenoid heating strips and a water' cooling system is also included to prevent overheating. During the extrusion process, the temperature is controlled by a thermal sensor and a PLC system. After getting out of the extrusion die head, bamboo plastic fiber will be checked size by PID system and then finished plastic fibers will be brought out by a roller system with cooling channels to stabilize their texture and surface. Finally, they are rolled into coils by an AC motor.

\subsection{System module analysis}

The primary analysis of modules that has the purpose of distinguishing to the main modules (machine detail cluster) of the machine, makes decision whether to combine these details into one module or whether different ones.

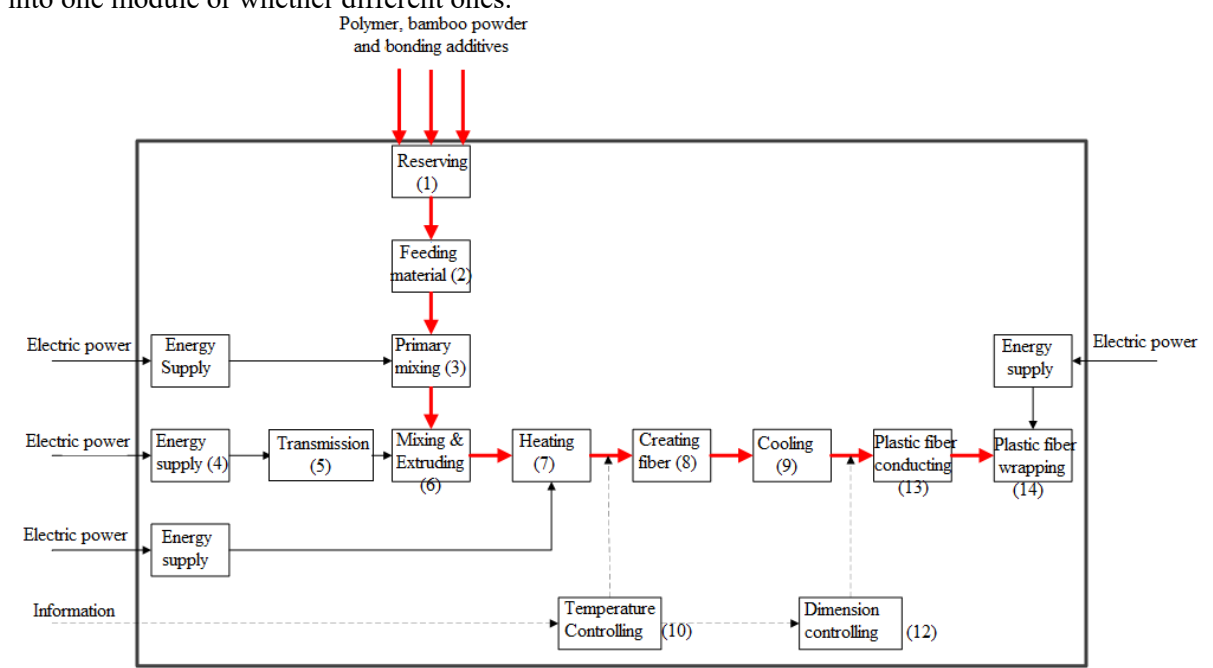

Fig. 5. Schema of primary arrangement and basic components in the system

\subsection{Structure module analysis}

Figure 5 displays the schematic analysis of the primary structure of the future machine. The structures after analysis are arranged in the direction of material flow from feeding to production. Figure 4 shows the basic functional-structure relationship diagram of the machine, in which functions are served by a set of components that can be called a "module". The power supply function is a special function that is included in each module.

The main function of the "Bamboo Wood Plastic Extrusion Machine for 3D Printer" is to perform the following processes: feeding, extruding and winding. The finished yarn is shown in Figure 6. 


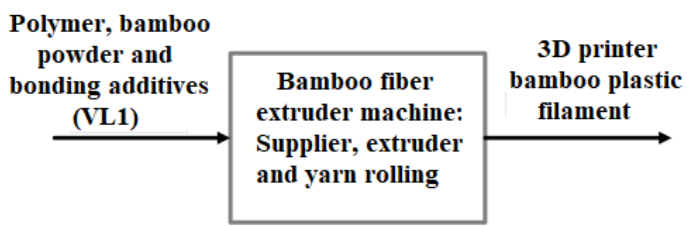

Fig. 6. Flowchart of general functions

When passing among the system, VL1 is supplied energy to change phase as well as to interact each other. After passing through all the components, it will vary in quantity and density, with or without synthesis with other materials. System-level parameters (SLP) between components are compared based on incoming and outgoing materials, material density synthesis and the variation.

The components in the system are then arranged in order to match the direction of movement of the material (Figure 7), in which the controller is temporarily removed from the system for easy analysis. The materials include bamboo powder, plastic beads and additives enters to the system through the fiber extrusion section. After being extruded into yarn, it will be rolled by the finished yarn winding unit.

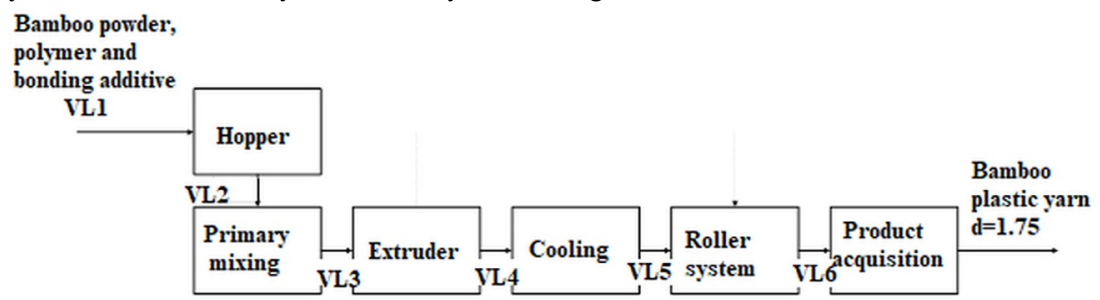

Fig. 7. Flowchart of function

Based on the functional flow diagram we determine the input and output relationships and compare them in the difference in size, similarity between materials or energy sources.

\begin{tabular}{|c|c|c|c|c|c|}
\hline Components & Designation & Input & Output & $\begin{array}{c}\text { Boundary } \\
\text { condition I/O }\end{array}$ & $\begin{array}{l}\text { Type of } \\
\text { function }\end{array}$ \\
\hline Hopper & $\mathrm{P}$ & VL1 & VL2 & $\mathrm{VL} 1=\mathrm{VL} 2$ & Sub ordinary \\
\hline $\begin{array}{c}\text { Primary } \\
\text { mixing module }\end{array}$ & TSC & VL2 & VL3 & VL2 $<$ VL3 & \\
\hline Electric motor & DCD & \multirow{5}{*}{ VL3 } & \multirow{5}{*}{ VL4 } & \multirow{5}{*}{ VL3<VL4 } & Main \\
\hline Gear & $\mathrm{BR}$ & & & & Main \\
\hline $\begin{array}{c}\text { Twin-screw \& } \\
\text { cylinder }\end{array}$ & TVD & & & & Main \\
\hline Heating & GN & & & & Main \\
\hline $\begin{array}{l}\text { Extruder } \\
\text { nozzle }\end{array}$ & $\mathrm{DD}$ & & & & main \\
\hline
\end{tabular}




\begin{tabular}{|c|c|c|c|c|c|}
\hline Components & Designation & Input & Output & $\begin{array}{c}\text { Boundary } \\
\text { condition I/O }\end{array}$ & $\begin{array}{c}\text { Type of } \\
\text { function }\end{array}$ \\
\hline $\begin{array}{c}\text { Cooling } \\
\text { system }\end{array}$ & KLM & VL4 & VL5 & VL4<VL5 & main \\
\hline Rolled system & CL & VL5 & VL6 & VL5=VL6 & main \\
\hline $\begin{array}{c}\text { Product } \\
\text { acquisition }\end{array}$ & TSP & & & & \\
\hline
\end{tabular}

\subsection{Properties of the products}

The technical parameters of "3D printed bamboo filament extrusion machine" are arranged in structural order. Based on the layout and state interaction between parts, the structural physics of the machine is divided to. In the schematic list of component pairs in a groups that have the relation of Serial connection, direct Interaction, homogeneity of material, compound effect, variable material, the pairs o groups do not appear in the comprehension map is considered to have the opposite properties. Note: N.T - Serial; S.S - Parallel; T.T Direct interaction; T.R - Separating; T.T - Direct; G.T - Indirect; T.D - Impact; K.T.D - No impact.

The 1 to 1 relationship of the components in the system is described via a System Level Specification (SLS). The requirements of SLS are located at the bottom of the hierarchical SLS diagram. Relationship are assigned to "1" if they exist, inversely to "0". The results of the basic component comparison process in the plastic filament extruder system are described in Table 1.

Table 1. The relation between structure and function

\begin{tabular}{|c|c|c|c|c|c|c|c|c|c|}
\hline \multirow{2}{*}{\multicolumn{2}{|c|}{ Detail/module }} & \multicolumn{4}{|c|}{ Physical Structure } & \multicolumn{4}{|c|}{ Function } \\
\hline & & \multicolumn{2}{|c|}{ Arrangement } & \multicolumn{2}{|c|}{ Position } & \multicolumn{2}{|c|}{ Energy } & \multicolumn{2}{|c|}{ Transmission } \\
\hline & & NT & SS & TT & TR & TT & GT & TD & KTD \\
\hline \multirow{9}{*}{$\mathbf{P}$} & TSC & 1 & 0 & 1 & 0 & 0 & 1 & 0 & 1 \\
\hline & DCD & 0 & 1 & 0 & 1 & 0 & 1 & 0 & 1 \\
\hline & BR & 0 & 1 & 0 & 1 & 0 & 1 & 0 & 1 \\
\hline & TVD & 0 & 1 & 0 & 1 & 0 & 1 & 0 & 1 \\
\hline & GN & 0 & 1 & 0 & 1 & 0 & 1 & 0 & 1 \\
\hline & DD & 0 & 1 & 0 & 1 & 0 & 1 & 0 & 1 \\
\hline & KLM & 0 & 1 & 0 & 1 & 0 & 1 & 0 & 1 \\
\hline & $\mathbf{C L}$ & 0 & 1 & 0 & 1 & 0 & 1 & 0 & 1 \\
\hline & TSP & 0 & 1 & 0 & 1 & 0 & 1 & 0 & 1 \\
\hline \multirow{8}{*}{ TSC } & DCD & 0 & 1 & 0 & 1 & 0 & 1 & 0 & 1 \\
\hline & BR & 0 & 1 & 0 & 1 & 0 & 1 & 0 & 1 \\
\hline & TVD & 0 & 1 & 0 & 1 & 0 & 1 & 0 & 1 \\
\hline & GN & 0 & 1 & 0 & 1 & 0 & 1 & 0 & 1 \\
\hline & DD & 0 & 1 & 0 & 1 & 0 & 1 & 0 & 1 \\
\hline & KLM & 0 & 1 & 0 & 1 & 0 & 1 & 0 & 1 \\
\hline & CL & 0 & 1 & 0 & 1 & 0 & 1 & 0 & 1 \\
\hline & TSP & 0 & 1 & 0 & 1 & 0 & 1 & 0 & 1 \\
\hline DCD & BR & 1 & 0 & 1 & 0 & 1 & 0 & 1 & 0 \\
\hline
\end{tabular}




\begin{tabular}{|c|c|c|c|c|c|c|c|c|c|}
\hline & TVD & 1 & 0 & 1 & 0 & 1 & 0 & 1 & 0 \\
\hline & GN & 1 & 0 & 1 & 0 & 1 & 0 & 1 & 0 \\
\hline & DD & 1 & 0 & 1 & 0 & 1 & 0 & 1 & 0 \\
\hline & KLM & 0 & 1 & 0 & 1 & 0 & 1 & 0 & 1 \\
\hline & CL & 0 & 1 & 0 & 1 & 0 & 1 & 0 & 1 \\
\hline & TSP & 0 & 1 & 0 & 1 & 0 & 1 & 0 & 1 \\
\hline \multirow{6}{*}{ BR } & TVD & 1 & 0 & 1 & 0 & 1 & 0 & 1 & 0 \\
\hline & GN & 1 & 0 & 1 & 0 & 1 & 0 & 1 & 0 \\
\hline & DD & 1 & 0 & 1 & 0 & 1 & 0 & 1 & 0 \\
\hline & KLM & 0 & 1 & 0 & 1 & 0 & 1 & 0 & 1 \\
\hline & CL & 0 & 1 & 0 & 1 & 0 & 1 & 0 & 1 \\
\hline & TSP & 0 & 1 & 0 & 1 & 0 & 1 & 0 & 1 \\
\hline \multirow{5}{*}{ TVD } & GN & 0 & 1 & 1 & 0 & 1 & 0 & 1 & 0 \\
\hline & DD & 1 & 0 & 1 & 0 & 1 & 0 & 1 & 0 \\
\hline & KLM & 0 & 1 & 0 & 1 & 0 & 1 & 0 & 1 \\
\hline & CL & 0 & 1 & 0 & 1 & 0 & 1 & 0 & 1 \\
\hline & TSP & 0 & 1 & 0 & 1 & 0 & 1 & 0 & 1 \\
\hline \multirow{4}{*}{ GN } & DD & 0 & 1 & 1 & 0 & 1 & 0 & 1 & 0 \\
\hline & KLM & 0 & 1 & 0 & 1 & 0 & 1 & 0 & 1 \\
\hline & CL & 0 & 1 & 0 & 1 & 0 & 1 & 0 & 1 \\
\hline & TSP & 0 & 1 & 0 & 1 & 0 & 1 & 0 & 1 \\
\hline \multirow{3}{*}{ DD } & KLM & 0 & 1 & 0 & 1 & 0 & 1 & 0 & 1 \\
\hline & $\mathbf{C L}$ & 0 & 1 & 0 & 1 & 0 & 1 & 0 & 1 \\
\hline & TSP & 0 & 1 & 0 & 1 & 0 & 1 & 0 & 1 \\
\hline \multirow{2}{*}{ KLM } & CL & 1 & 0 & 0 & 1 & 1 & 0 & 1 & 0 \\
\hline & TSP & 1 & 0 & 0 & 1 & 1 & 0 & 1 & 0 \\
\hline CL & TSP & 1 & 0 & 0 & 1 & 1 & 0 & 1 & 0 \\
\hline
\end{tabular}

The impact of System Level Specification (SLS) to the General Function Requirements (GFR):

Determining the impact of SLS on GFR is to identify properties that could have a positive or negative impact on the general function of the system. Relationships are more clearly defined, the easier to develop the texture of the product and to achieve a high level of satisfaction to the customers requirements as well as all the recommended specification.

The impact of SLS is determined on customers requirements by the following questions such as:

-What happens to GFR with or without any SLS in the system?

-What kind of effects of SLS will cause GFR?

All the answers of the above questions will help to determine the impact of SLS on GFR.

The impact of SLS on GFR is evaluated on the customer requirements where decisive factors are functional assurance, product size and operational productivity. The sequential layout of the components facilitates the ability of application of the product... In addition, the serial arrangement ensures the compactness of the product and while not having any effect on the performance, productivity. The parallel layout is suitable for the compact size of the product, while also having a positive effect on work efficiency when multiple machines are working at the same time.

Direct interaction between details does not affect the performance of the system. Direct interaction has a positive effect on the level of compactness, the closer the details are, the 
more compact the product is. In addition, direct interaction aids also the performance when materials are directly transported.

Separate components make the maintenance easier, but it increases the sizes and has a negative impact on the compactness. The homogeneity and impurity of the material has positive effect on the performance of the product, due to the requirement of transportation, synthesis or modification of the material. Homogeneous materials have a positive impact on performance since the operation only has to handle the same materials from input to output.

The modification of material ensures the workability and has no effect on product size or performance of the system. In the other hand, the non-impacting that has no effect on workability or size of the product, has also a positive effect on performance as it does not take energy to impact on materials.

Once the questions are answered, the effects are listed in Table 2, based on the values: - $(-1)=$ Negative impact

- (0) $=$ No impact or the impact is not clear, not determined.

- $(+1)=$ Positive effects

The negative impact of SLS on GFR causes the undesirable results when SLS is present in the system because it will restrict and reduce the level of compliance with specifications and customer requirements. Positive effects will create the desirable results to the GFR to ensure the satisfaction of the specifications of the products and the requirements of the customers. An SLS has no effect if it neither supports nor impedes the implementation of the overall functionality.

Table 2. The effect of the relation between SLS and GFR [12]

\begin{tabular}{|c|c|c|c|c|c|}
\hline \multirow{2}{*}{ SLS } & \multicolumn{3}{|c|}{ Requirement of general function } & \multirow{2}{*}{\multicolumn{2}{|c|}{ Weight }} \\
\hline & Assure the workability & Compact & Performance & & \\
\hline N.T & 1 & 1 & 0 & 1 & Function \\
\hline S.S & 0 & 0 & 1 & 1 & Compact \\
\hline T.T & 0 & 1 & 1 & 1 & Performance \\
\hline T.R & 0 & -1 & 0 & & \\
\hline T.T & 1 & 1 & 1 & 1 & Function \\
\hline G.T & 1 & 0 & -1 & 1 & Compact \\
\hline T.D & 1 & 0 & 0 & 1 & Performance \\
\hline $\mathrm{KTD}$ & 1 & 0 & 0 & & \\
\hline
\end{tabular}

\section{Results and Discussion}

\subsection{Calculation of matrix of similarity}

Matrices of similarity are used to determine the degree of coherence among the different components in the system. The similarity matrix is established based on the similarity indices, which are the result of 3-matrix multiplication: SLS, effect of SLS on GFR, Weight of GFR. Each value in the similarity matrix represents a 1 to 1 relationship between the components of the system. Calculations were performed by Microsoft ${ }^{\circledR}$ Excel software and listed the results in the tables below. 
Table 3. Matrix of Similarity of structure

\begin{tabular}{|c|c|c|c|c|c|c|c|c|c|c|}
\hline \multicolumn{10}{|c|}{} & \multicolumn{10}{c|}{ Matrix of similarity of structure } \\
\hline P & P & ISC & DCD & BR & TVD & GN & DD & KLM & CL & ISP \\
\hline TSC & 4 & 0 & 0 & 0 & 0 & 0 & 0 & 0 & 0 & 0 \\
\hline DCD & 0 & 0 & 0 & 4 & 4 & 4 & 4 & 0 & 0 & 0 \\
\hline BR & 0 & 0 & 4 & 0 & 4 & 4 & 4 & 0 & 0 & 0 \\
\hline TVD & 0 & 0 & 4 & 4 & 0 & 3 & 4 & 0 & 0 & 0 \\
\hline GN & 0 & 0 & 4 & 4 & 3 & 0 & 3 & 0 & 0 & 0 \\
\hline DD & 0 & 0 & 4 & 4 & 4 & 3 & 0 & 0 & 0 & 0 \\
\hline KLM & 0 & 0 & 0 & 0 & 0 & 0 & 0 & 0 & 1 & 1 \\
\hline CL & 0 & 0 & 0 & 0 & 0 & 0 & 0 & 1 & 0 & 1 \\
\hline ISP & 0 & 0 & 0 & 0 & 0 & 0 & 0 & 1 & 1 & 0 \\
\hline
\end{tabular}

Table 4. Matrix of similarity of function

\begin{tabular}{|c|c|c|c|c|c|c|c|c|c|c|}
\hline \multicolumn{11}{|c|}{ Matrix of similarity of function } \\
\hline$>0$ & $\mathbf{P}$ & ISC & $\mathrm{DCD}$ & $\mathrm{BR}$ & TVD & GN & $\mathrm{DD}$ & KLM & $\mathrm{CL}$ & TSP \\
\hline $\mathbf{P}$ & 0 & 1 & 1 & 1 & 1 & 1 & 1 & 1 & 1 & 1 \\
\hline TSC & 1 & 0 & 1 & 1 & 1 & 1 & 1 & 1 & 1 & 1 \\
\hline DCD & 1 & 1 & 0 & 4 & 4 & 4 & 4 & 1 & 1 & 1 \\
\hline $\mathrm{BR}$ & 1 & 1 & 4 & 0 & 4 & 4 & 4 & 1 & 1 & 1 \\
\hline TVD & 1 & 1 & 4 & 4 & 0 & 4 & 4 & 1 & 1 & 1 \\
\hline GN & 1 & 1 & 4 & 4 & 4 & 0 & 4 & 1 & 1 & 1 \\
\hline $\mathrm{DD}$ & 1 & 1 & 4 & 4 & 4 & 4 & 0 & 1 & 1 & 1 \\
\hline KLM & 1 & 1 & 1 & 1 & 1 & 1 & 1 & 0 & 4 & 4 \\
\hline $\mathrm{CL}$ & 1 & 1 & 1 & 1 & 1 & 1 & 1 & 4 & 0 & 4 \\
\hline TSP & 1 & 1 & 1 & 1 & 1 & 1 & 1 & 4 & 4 & 0 \\
\hline
\end{tabular}

Table 5. Matrix of general similarity

\begin{tabular}{|c|c|c|c|c|c|c|c|c|c|c|}
\hline \multicolumn{10}{|c|}{ Matrix of general similarity } \\
\hline P & P & TSC & DCD & BR & TVD & GN & DD & KLM & CL & ISP \\
\hline ISC & 0 & 5 & 1 & 1 & 1 & 1 & 1 & 1 & 1 & 1 \\
\hline DCD & 5 & 0 & 1 & 1 & 1 & 1 & 1 & 1 & 1 & 1 \\
\hline BR & 1 & 1 & 0 & 8 & 8 & 8 & 8 & 1 & 1 & 1 \\
\hline IVD & 1 & 1 & 8 & 0 & 8 & 8 & 8 & 1 & 1 & 1 \\
\hline GN & 1 & 1 & 8 & 8 & 0 & 7 & 8 & 1 & 1 & 1 \\
\hline DD & 1 & 1 & 8 & 8 & 8 & 7 & 0 & 1 & 1 & 1 \\
\hline KLM & 1 & 1 & 1 & 1 & 1 & 1 & 1 & 0 & 5 & 5 \\
\hline CL & 1 & 1 & 1 & 1 & 1 & 1 & 1 & 5 & 0 & 5 \\
\hline TSP & 1 & 1 & 1 & 1 & 1 & 1 & 1 & 5 & 5 & 0 \\
\hline
\end{tabular}

\subsection{Group of components of modules}

When the number of components in the system not too large, using Cluster Identification Algorithm (CIA) to arrange similar matrices into independent modules. The results are shown in the tables below. 
Table 6. Module of structure

\begin{tabular}{|c|c|c|c|c|c|c|c|c|c|c|}
\hline \multicolumn{11}{|c|}{ Module of structure } \\
\hline $7>$ & $P$ & ISC & $\mathrm{DCD}$ & BR & TVD & GN & DD & KLM & $\mathrm{CL}$ & ISP \\
\hline$P$ & 0 & 4 & 0 & 0 & 0 & 0 & 0 & 0 & 0 & 0 \\
\hline ISC & 4 & 0 & 0 & 0 & 0 & 0 & 0 & 0 & 0 & 0 \\
\hline$\overline{\mathrm{DCD}}$ & 0 & 0 & 0 & 4 & 4 & 4 & 4 & 0 & 0 & 0 \\
\hline BR & 0 & 0 & 4 & 0 & 4 & 4 & 4 & 0 & 0 & 0 \\
\hline TVD & 0 & 0 & 4 & 4 & 0 & 3 & 4 & 0 & 0 & 0 \\
\hline GN & 0 & 0 & 4 & 4 & 3 & 0 & 3 & 0 & 0 & 0 \\
\hline $\mathrm{DD}$ & 0 & 0 & 4 & 4 & 4 & 3 & 0 & 0 & 0 & 0 \\
\hline KLM & 0 & 0 & 0 & 0 & 0 & 0 & 0 & 0 & 1 & 1 \\
\hline $\mathrm{CL}$ & 0 & 0 & 0 & 0 & 0 & 0 & 0 & 1 & 0 & 1 \\
\hline TSP & 0 & 0 & 0 & 0 & 0 & 0 & 0 & 1 & 1 & 0 \\
\hline
\end{tabular}

Table 7. Module of function

\begin{tabular}{|c|c|c|c|c|c|c|c|c|c|c|}
\hline \multicolumn{11}{|c|}{ Module of function } \\
\hline 96 & $P$ & TSC & $\mathrm{DCD}$ & BR & TVD & GN & $\mathrm{DD}$ & KLM & $\mathrm{CL}$ & TSP \\
\hline$P$ & 0 & 1 & 1 & 1 & 1 & 1 & 1 & 1 & 1 & 1 \\
\hline ISC & 1 & 0 & 1 & 1 & 1 & 1 & 1 & 1 & 1 & 1 \\
\hline DCD & 1 & 1 & 0 & 4 & 4 & 4 & 4 & 1 & 1 & 1 \\
\hline BR & 1 & 1 & 4 & 0 & 4 & 4 & 4 & 1 & 1 & 1 \\
\hline TVD & 1 & 1 & 4 & 4 & 0 & 4 & 4 & 1 & 1 & 1 \\
\hline GN & 1 & 1 & 4 & 4 & 4 & 0 & 4 & 1 & 1 & 1 \\
\hline $\mathrm{DD}$ & 1 & 1 & 4 & 4 & 4 & 4 & 0 & 1 & 1 & 1 \\
\hline KLM & 1 & 1 & 1 & 1 & 1 & 1 & 1 & 0 & 4 & 4 \\
\hline $\mathrm{CL}$ & 1 & 1 & 1 & 1 & 1 & 1 & 1 & 4 & 0 & 4 \\
\hline TSP & 1 & 1 & 1 & 1 & 1 & 1 & 1 & 4 & 4 & 0 \\
\hline
\end{tabular}

Table 8. Synthetic module

\begin{tabular}{|c|c|c|c|c|c|c|c|c|c|c|}
\hline \multicolumn{11}{|c|}{ Synthetic module } \\
\hline > & $\mathbf{P}$ & TSC & $\mathrm{DCD}$ & $\mathrm{BR}$ & TVD & GN & $\mathrm{DD}$ & KLM & $\mathrm{CL}$ & ISP \\
\hline$P$ & 0 & 5 & 1 & 1 & 1 & 1 & 1 & 1 & 1 & 1 \\
\hline TSC & 5 & 0 & 1 & 1 & 1 & 1 & 1 & 1 & 1 & 1 \\
\hline$D C D$ & 1 & 1 & $\overline{0}$ & 8 & 8 & 8 & 8 & 1 & 1 & 1 \\
\hline BR & 1 & 1 & 8 & 0 & 8 & 8 & 8 & 1 & 1 & 1 \\
\hline TVD & 1 & 1 & 8 & 8 & 0 & 7 & 8 & 1 & 1 & 1 \\
\hline GN & 1 & 1 & 8 & 8 & 7 & 0 & 7 & 1 & 1 & 1 \\
\hline $\mathrm{DD}$ & 1 & 1 & 8 & 8 & 8 & 7 & 0 & 1 & 1 & 1 \\
\hline KLM & 1 & 1 & 1 & 1 & 1 & 1 & 1 & 0 & 5 & 5 \\
\hline $\mathrm{CL}$ & 1 & 1 & 1 & 1 & 1 & 1 & 1 & 5 & 0 & 5 \\
\hline ISP & 1 & 1 & 1 & 1 & 1 & 1 & 1 & 5 & 5 & 0 \\
\hline
\end{tabular}

Components with a degree of cohesion (high similarity index) are grouped into a group that can be considered a module. The other components that are outside the established group due to low degree of association with each other and for groups, are relative and indirectly related. There are also some components that have similar indices for one or more other components that are well above the floor value, perform the function of linking components or having relative relationships of interactions or materials. The results show that there are 3 modules of physical structure, including feed, extruder, control and cooling and 4 function modules.

Based on the synthetic module matrix, we can divide the designed machine into 4 modules:

- Module I: Extrusion module: Electric motor gearbox; Flexible coupling; Cylindrical gear.

Twin screw facing outwards; Extrusion head; Cylinder; Heating solenoid. 
- Module II: Product acquisition module: Controlled servo motor; Flexible coupling; Plastic fiber reel; Roller system; Cooling channel.

- Module III: Control module: Temperature sensor; PID system; PLC system.

- Module IV: Feeding Module: Hopper; AC motor mixer; Mixers.

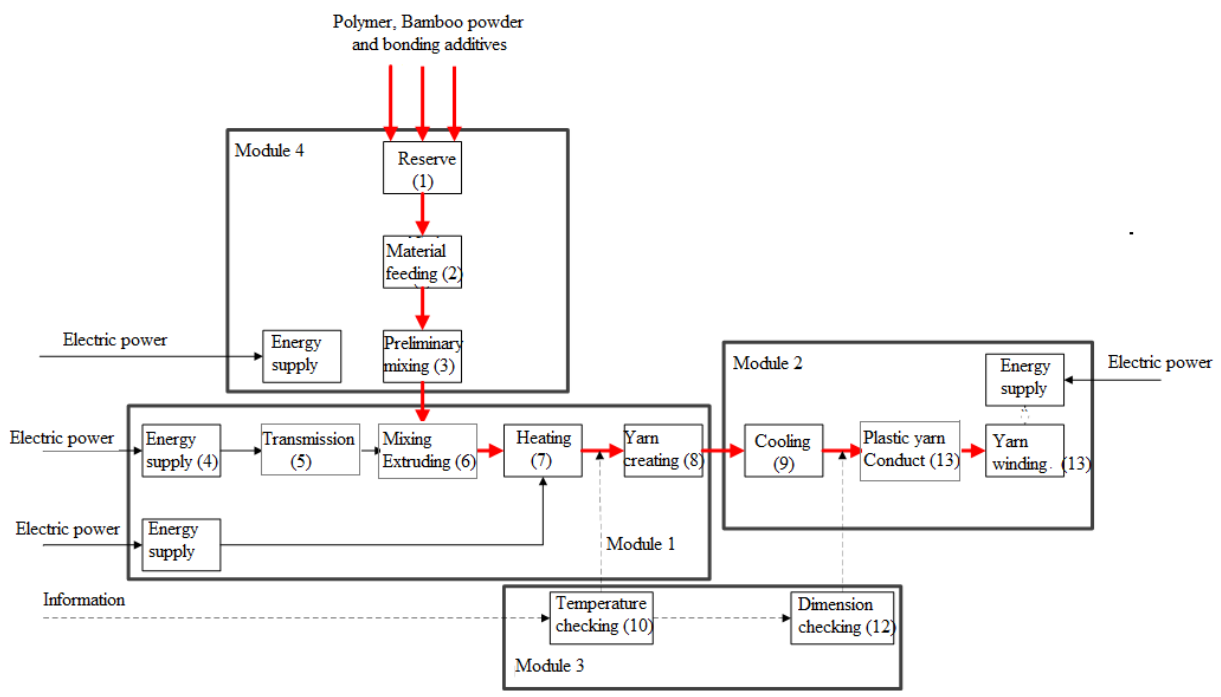

Fig. 8. Layout of modules of the designed machine

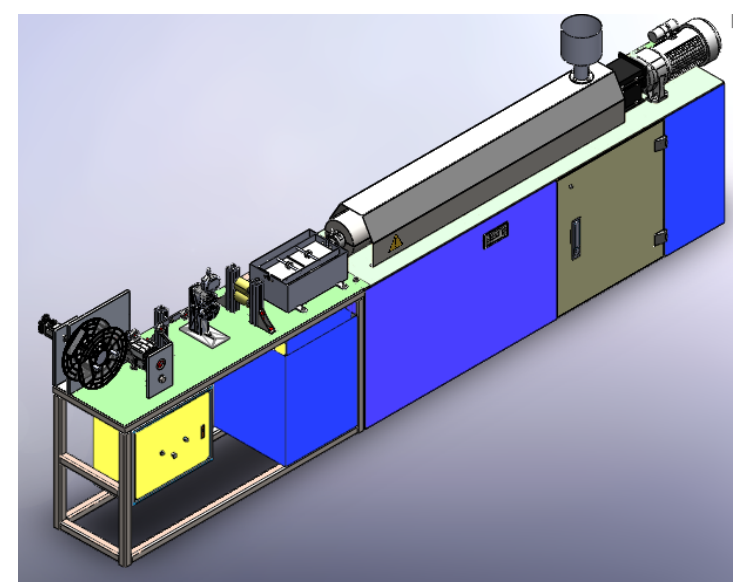

Fig. 9. General model of the machine 


\section{Conclusion}

With the application of Cluster Identification Algorithm (CIA) in modular approach to design the bamboo plastic fiber forming machine we can achieve reasonable design gain lot of advantages: satisfy customers; requirements, efficient in working, high performance and competitive price. In the other hand, it helps designers reduce design time and fabrication costs because there are many mechanical parts to choose from on the market. We hope that the research has a valuable position in the modern design.

\section{References}

1. S. S. Muthu. Green Composites: Sustainable Raw Materials (Springer Nature, Singapore, 2019).

2. N. Stark, Influence of Moisture Absorption on Mechanical Properties of Wood FlourPolypropylene Composites, Journal of Thermoplastic Composite Materials, 14(2001).

3. K. Yuvaraj, M.P. Thirumoorthy, S. Ramalingam, C. Ravikumar, R. Swaminathan, Mechanical properties of pineapple, banana and bamboo fiber reinforced epoxy hybrid composite systta, International Journal of Research in Engineering and Managta ent [IJRTA], vol 1, no 1, pp. 270-276, 2019.

4. L. Chaunier, S. Guessasma, S. Belhabib, G.D. Valle, D. Lourdin, E. Leroy, Material extrusion of plant biopolymers: Opportunities \& challenges for $3 D$ printing, Additive Manufacturing, 21, (2018).

5. D. Zhao, X. Cai, G. Shou, Y. Gu, P. Wang, Study on the Preparation of Bamboo Plastic Composite Intend for Additive Manufacturing, Key Engineering Materials, Vol. 667 (2016).

6. 3d printing for beginners. How to make DIY Filament for your 3D Printer, 2018, [Online]. Available: http://3dprintingforbeginners.com/wpcontent/uploads/2014/05/How-to-make-DIY-Filament-for-your-3DPrinter Download.pdf. [Access on Jan 10, 2019].

7. H. Long, Z. Wu, Q. Dong, Y. Shen, W. Zhou, Y. Luo, C. Zhang, X. Dong, Mechanical and Thermal Properties of Bamboo Fiber Reinforced Polypropylene/Polylactic Acid Composites for 3D Printing, Polymer Engineering \& Science, Vol. 59 (2019).

8. Double-screw extrusion machine, CN204123647U, 2014.

9. N. T. Nam. Mechanical Design Process, VNU HCM Press, Ho Chi Minh City, 2014.

10. A. Svetlin, K.D. Le, H.H. Nguyen, H.Q.H. Nguyen, and H.Q. Hoang, A Design of Plastic-Bamboo Fiber Extruder Machine for $3 D$ Printe, Applied Mechanics and Materials, Vol. 902 (2020).

11. N.H. Hiep, The manufacturing technology of bamboo-plastic-fibers for $3 D$ printers, Master thesis, 2020.

12. A.K. Kamrani, S.M. Salhieh. Product Design for Modularity, Springer US, 2002. 